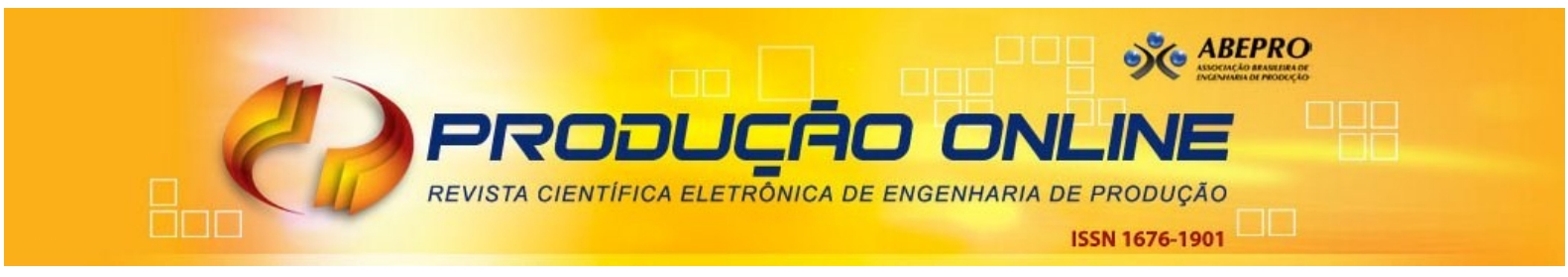

\title{
COMPETÊNCIAS ESSENCIAIS PRESENTES EM FRIGORIFICOS BRASILEIROS EXPORTADORES PARA A EUROPA: UM ESTUDO MULTICASO
}

\section{CORE COMPETENCES OF BRAZILIAN BEEF EXPORTERS TO EUROPE: A MULTI-CASE STUDY}

\author{
José Stamato Neto* E-mail: jstamato42@hotmail.com \\ Rosane L. Chicarelli Alcantara*E-mail: rosane@ufscar.br \\ *Universidade Federal de São Carlos (UFSCAR), São Carlos, SP
}

\begin{abstract}
Resumo: Uma competência pode ser considerada essencial quando é fonte de vantagem competitiva para a empresa que a possui, sendo vista como recurso essencial para que a empresa possa prover produtos/ serviços diferenciados em relação a mercados e clientes. Este trabalho parte da aceitação do fato de que as competências essenciais existentes nos frigoríficos brasileiros afetam em diferentes níveis a sua capacidade de exportação para a União Europeia. Diante disso, o objetivo deste artigo é apresentar as competências essenciais presentes nos frigoríficos brasileiros exportadores de carne in natura para Europa, classificando-as em sustentáveis e temporárias. Com os resultados obtidos espera-se auxiliar os gestores de frigoríficos a desenvolverem essas competências, aumentando assim sua competitividade no mercado externo. A metodologia utilizada foi um Estudo Multicaso com a finalidade de identificar e estruturar essas competências a partir do que ocorre nas organizações pesquisadas. Os resultados apontam a existência de 19 competências essenciais que suportam as exportações de carne bovina destes frigoríficos para a União Européia. Vale destacar que nas empresas em questão são as competências baseadas em recursos intangíveis, como conhecimento do mercado, tradição e reputação, que alavancam essas exportações.
\end{abstract}

Palavras-chave: Carne Bovina. Capacitações. Competências Essenciais. Exportações.

Abstract: The main objective of the research was the analysis of the core competences of some of the most important Brazilian beef processors and exporters to European Union. These core competencies are sources of competitive advantage and could allow Brazilian beef processors increasing their competitiveness. The research was structured as a multi-case study. The research mapped 19 core competences which support beef exports to the European Union. The most important core competences which leverage Brazilian beef exports to European Union and impact the structuring of marketing channels in the European market are core competences based on intangible resources, such as market knowledge, tradition and reputation. These core competencies can allow Brazilian beef processors to gradually establish long term relationships in the marketing channels with their clients.

Keywords: Brazilian beef. Capabilities. Core Competences. Exports.

\section{INTRODUÇÃo}

Num contexto de economia mundial em constante e rápida evolução, a comercialização de bens e serviços se faz em ambientes cada vez mais complexos e instáveis. O conhecimento dos mercados, particularmente dos distribuidores, 
consumidores e dos arranjos de comercialização utilizados, ou que possam a vir ser implantados, torna-se fundamental para a sobrevivência e desenvolvimento de empresas (PALACIOS; SOUZA, 2004).

Neste novo cenário de negócios, o bom desempenho das empresas está diretamente relacionado à obtenção de vantagens competitivas sustentáveis. Essa perspectiva abre um leque de oportunidades de estudos sobre recursos, capacitações e competências essenciais, que constituem um ferramental de análise estratégica do ponto de vista interno das firmas.

Prahalad e Hamel (1990) consideram que as competências essenciais são resultado do aprendizado coletivo da organização, especialmente do aprendizado relacionado ao como coordenar as diversas habilidades de produção e integrar as múltiplas correntes de tecnologia. Isso, de acordo com Hoskisson et al. (2004), pode proporcionar a base para a criação de vantagens competitivas sustentáveis. DalSoto, Paiva e Souza (2007) e Knight e Cavusgil (2004) colocam a que internacionalização das empresas é um processo de aprendizagem apoiado em uma combinação de recursos e competências. Para Dal-Soto, Paiva e Souza (2007) essas competências podem ser agrupadas em três: (a) domínio da tecnologia de processo; (b) capacidade de entender os mercados e (c) a habilidade de agregar parceiros. Knight e Cavusgil (2004) destacam como competência importante a influencia dos distribuidores estrangeiros junto aos seus mercados.

Outra definição aponta que as competências essenciais são recursos intangíveis que são difíceis de serem imitados pelos concorrentes. São também recursos essenciais para que a empresa possa prover produtos/ serviços diferenciados em relação a mercados e clientes. De certa forma, o conceito de competências essenciais aproxima-se do conceito de capacitações. Entretanto, na ótica de Hoskisson et al. (2004) apenas aquelas capacitações que geram vantagens competitivas efetivas e sustentáveis podem ser consideradas competências essenciais.

A cadeia agroindustrial da carne bovina brasileira atualmente está totalmente inserida no contexto de negócios globais. Esta situação se contrasta com o posicionamento histórico desta cadeia que, por muito tempo, esteve voltada para o atendimento do mercado doméstico e a coloca frente ao desafio de atuar em mercados internacionais. Nesse sentido, Bragatto (2008) coloca que a 
implementação de uma visão empresarial em todos os elos desta cadeia produtiva torna-se necessária, com o objetivo de satisfazer as exigências relacionadas ao produto e aos mercados, buscando mecanismos de gestão eficientes para aumentar seus ganhos econômicos. Com isto, abrem-se perspectivas para a elaboração de novos estudos sobre a cadeia da carne bovina no Brasil, dentre os quais estudos que venham a contemplar a análise das competências essenciais existentes nos principais frigoríficos exportadores brasileiros, que viabilizam a comercialização de seus produtos em mercados internacionais.

Diante disso, o objetivo deste artigo é apresentar as competências essenciais presentes nos frigoríficos brasileiros exportadores de carne in natura para Europa, classificando-as em sustentáveis e temporárias.

A classificação destas competências em sustentáveis e temporárias se faz necessária para que as empresas possam se focar na busca das competências sustentáveis, dado que serão estas as responsáveis pela geração da vantagem competitiva a longo prazo (HOSKISSON et al. 2004). A importância deste artigo, sob a ótica acadêmica, é apresentar uma estrutura de análise da indústria brasileira de carne bovina através do conceito de competências essenciais, sendo que tal estrutura deverá ser refinada posteriormente através de pesquisas futuras. Do ponto de vista empresarial, a estrutura apresentada pode servir como ferramenta de análise para que outros frigoríficos de carne bovina possam determinar suas próprias competências essenciais, e verificar se estas são condizentes com as competências essenciais relatadas nesta pesquisa ou se novas competências devem ser buscadas.

\section{RECURSOS, CAPACITAÇÕES E COMPETÊNCIAS ESSENCIAIS}

Os debates sobre os fatores que determinam a competitividade das empresas têm sido enriquecidos nos últimos anos com novas abordagens. $O$ enfoque clássico é a 'análise da indústria' ou do 'posicionamento estratégico', que prioriza a análise dos mercados e da competição e o entendimento da posição relativa de cada empresa em sua indústria ou segmento produtivo como elementos primordiais no processo de formulação da estratégia. Esta visão fica evidente quando Porter (1986) menciona que a essência de formulação de uma estratégia competitiva é relacionar 
uma companhia ao seu meio ambiente. Neste sentido, Piovezan, Laurindo e Carvalho (2008) destacam que o processo de elaboração da estratégia empresarial passa por adequar as competências da empresa ao ambiente onde ela esta inserida, de forma a torna-la mais competitiva que seus concorrentes. Por outro lado, a falta de habilidade da organização em construir as competências necessárias, pode representar um risco a sua sobrevivência no longo prazo (Abe e Carvalho, 2011)

Apesar de sua importância, a análise do posicionamento estratégico não foi historicamente o único modelo utilizado para se determinar porque algumas empresas criam vantagens competitivas sustentáveis ao longo do tempo e outras não. De acordo com Sanchez e Heene (2004), desde a década de 1950 existem autores, notadamente Selznick (1957) e Penrose (1959), que argumentam que qualquer forma de vantagem competitiva sustentável que uma firma possa desenvolver resulta de uma combinação única de recursos da empresa.

De todo modo, esta visão baseada em recursos internos da empresa como fator gerador de vantagens competitivas sustentáveis ganhou corpo somente na década de 1980. Em 1984, Wernerfelt publicou o artigo que lançou as bases para o conceito de Resource-Based View (RBV), ou Visão Baseada em Recursos. Esta visão é corroborada por Ghemawat (2000) que afirma que a visão baseada em recursos é uma ideia antiga que foi revivida em 1984 em um artigo de Wernerfelt (1984).

Para Henderson e Cockburn (2000), ocorreu um retorno no interesse de pesquisadores como Lippman e Rumelt (1982); Wernerfelt (1984); Barney (1986); Rumelt (1991); Amit e Schoemaker (1993); Dosi e Teece (1993) e Peteraf (1993), nesse tema. Os trabalhos nesta linha de pesquisa buscaram inspiração em Selznick (1957) e Penrose (1959) e sugerem que a heterogeneidade inimitável da firma, ou a posse de "capacitações" ou "competências" únicas pode ser uma importante e duradoura fonte de vantagem competitiva. Na ótica de Henderson e Cockburn (2000), esta perspectiva passou a ser um complemento importante para desenvolvimento no campo da gestão estratégica.

Segundo Fahy e Smithee (1999), a lógica básica da visão baseada em recursos é relativamente simples. Ela começa com a premissa de que adquirir uma vantagem competitiva sustentável possibilita à firma obter resultados econômicos 
acima da média de determinada indústria e/ou setor. A visão baseada em recursos apregoa que a resposta a esta busca baseia-se na posse de certos recursos básicos, recursos estes que possuem características como 'valor', 'barreiras para duplicação' e 'capacidade de apropriação'. Uma vantagem competitiva sustentável ocorre se a firma efetivamente dispõe desses recursos em seu mercado de atuação.

Portanto, a visão baseada em recursos enfatiza uma opção estratégica da firma no sentido de encarregar seus gestores da importante tarefa de identificar, desenvolver e tornar acessível, dentro da empresa, estes recursos básicos, de forma a maximizar Seu Retorno Econômico.

Para Anderson e Narus (2004), a visão baseada em recursos vê as empresas como conjuntos distintos de ativos físicos, ativos intangíveis e capacitações. Nenhuma companhia é igual à outra porque nenhuma companhia possui a mesma gama de experiências, adquiriu os mesmos ativos ou as mesmas habilidades, ou construiu a mesma cultura organizacional.

De acordo com Sanchez e Heene (2004), o artigo de Wernerfelt (1984) serviu de base para que outros autores pudessem desenvolver seus próprios modelos, que consideram os recursos da empresa como base para sua vantagem competitiva. Barney (1997) popularizou o conceito de Value Resources Imitability Organization (VRIO), que é um modelo que propõe que a análise interna dos pontos fortes e fracos de uma empresa deveria levar em consideração quatro questões sobre a natureza e o uso de recursos da uma firma:

1. A questão do valor: os recursos de uma firma a possibilitam responder a ameaças e oportunidades oriundas do meio-ambiente?

2. A questão da raridade: quantas empresas concorrentes já detêm estes recursos valiosos?

3. A questão da capacidade de imitação: as empresas que não detêm estes recursos valiosos possuem uma desvantagem de custos em relação às empresas que já possuem tais recursos valiosos?

4. A questão da organização: trata-se de uma empresa com a capacidade de fazer pleno uso de seus recursos de forma a obter uma vantagem competitiva sustentável?

Um ponto interessante da abordagem de Fahy e Smithee (1999) diz respeito à ênfase na ligação existente entre recursos internos das empresas e as condições 
de mercado, relação esta que muitas vezes é negligenciada. AMIT e Schoemaker (1993) e Collins e Montgomery (1995) são autores que também fazem essa conexão entre os recursos internos das empresas e as condições de mercado, de acordo com Fahy e Smithee (1999).

Hooley et al. (1997) apud Fahy e Smithee (1999) criticam a visão baseada em recursos por seu foco excessivamente interno, ressaltando-se que ao usa-la, podese correr o risco de se ignorar as demandas do mercado.

Grant (2005) faz uma importante distinção entre os recursos de uma firma e suas capacitações. Este autor caracteriza os recursos como insumos para os processos de produção da firma, mas ressalta que apenas alguns poucos desses recursos são, de fato, insumos para um processo produtivo. Desta forma ele ressalta que são poucos os recursos que efetivamente diferenciam o processo de produção de uma empresa. Para que a firma produza algo, os recursos precisam ser coordenados, e uma capacitação surge justamente como resultado do ato de uma firma coordenar seus recursos efetivamente ao realizar alguma tarefa ou atividade.

Ou seja, para Grant (2005), a existência dos recursos é essencial para a criação das capacitações de uma firma, mas são as capacitações a fonte de qualquer vantagem competitiva sustentável que a firma adquire no mercado.

Já para Dranove e Marciano (2005), os recursos seriam como substantivos, ou 'itens' que as firmas possuem. É geralmente fácil identificar os recursos-chave das organizações bem sucedidas. Os autores citam o caso da Avon, que possui uma ampla linha de cosméticos de boa qualidade e um time de vendedoras leais, que possui relacionamento muito próximo de suas consumidoras. Já o eBay possui uma tecnologia diferenciada para realizar leilões on-line e uma grande base instalada de vendedores e compradores. Capacitações seriam verbos, na ótica de Dranove e

Marciano (2005). Em outras palavras, as capacitações demonstram o que as empresas fazem com seus recursos. A Avon, segundo os autores, torna o processo de compra em algo divertido, enquanto que o eBay, além de tornar o processo de compra divertido, também garante aos participantes os melhores preços possíveis.

Craig e Grant (1999), afirmam que a análise das capacitações começa com a classificação das atividades da empresa. Antes de perguntar: 'O que a empresa faz eficientemente?', é necessário primeiro indagar: 'O que a empresa faz?'. Um motivo comum do fracasso dos negócios não é a ausência de capacitações, mas a 
inabilidade de reconhecer quais são elas e colocá-las em prática. Portanto, a análise das capacitações deve começar com um reconhecimento cuidadoso das atividades que a empresa desempenha. Ou seja, os recursos são os patrimônios específicos da empresa: bens de capital, qualificação dos funcionários, patentes, marcas e similares. As capacitações são o que a empresa pode fazer: o resultado dos recursos trabalhando em conjunto para realizar tarefas produtivas.

Besanko et al. (2004) fazem uma comparação semelhante à realizada por Dranove e Marciano (2005), ao definirem os recursos como substantivos (os itens que as firmas possuem), enquanto que as capacitações são os itens que a firma faz. Laserre (2003) menciona a relação intrínseca entre capacitações e vantagens competitivas. Segundo este autor, vantagens competitivas são capacitações difíceis de serem imitadas, replicadas e que são não comercializáveis. Interessante notar que estas características também são a base para conceituar competências essenciais, sendo, portanto, possível inferir uma correlação entre capacitações, competências essenciais e vantagens competitivas. De forma geral, é possível distinguir dois tipos de capacitações que levam a vantagens competitivas:

a. Capacitações que levam à geração de valor para o consumidor através de desempenho, qualidade, serviços e marca (reputação), por intermédio de uma proposição de diferenciação;

b. Capacitações que levam a uma situação de custos mais baixos, como mão-de-obra mais barata, matéria-prima mais barata, economias de escala e eficiência, por meio de uma proposição de liderança em custos.

De acordo com Hoskisson et al. (2004) alguns recursos são tangíveis, enquanto outros são intangíveis. Recursos tangíveis são ativos que podem ser observados e quantificados. Equipamentos pertencentes à linha de produção e as próprias plantas industriais são exemplos de recursos tangíveis. Já os recursos intangíveis incluem ativos que estão profundamente enraizados na história da firma e são acumulados ao longo do tempo. Pelo fato de estarem estabelecidos em padrões únicos e exclusivos de rotina, os recursos intangíveis são difíceis de serem analisados e copiados pelos competidores. Conhecimento, confiança entre funcionários e gerentes, ideias, capacidade de inovação, competências gerenciais, rotinas organizacionais (maneiras únicas das pessoas trabalharem em conjunto), capacitações científicas, a reputação da empresa e como a empresa interage com 
as pessoas (funcionários, clientes e fornecedores), são todos exemplos de recursos intangíveis. Os quatro tipos de recursos tangíveis são: financeiros, organizacionais, físicos e tecnológicos. Já os três tipos de recursos intangíveis são os recursos humanos, inovadores e de reputação. (BARNEY, 1991; GRANT, 1991, apud HOSKISSON et al., 2004).

De acordo com Hoskisson et al. (2004) os recursos, as capacitações e as competências essenciais são as características que proporcionam a base para a criação de vantagem competitiva para as empresas. $\mathrm{Na}$ verdade essas características estão interrelacionadas na medida em que os recursos são a fonte das capacitações das empresas que são, por sua vez, a fonte das competências essenciais, sendo estas ultimas a base das vantagens competitivas.

O conceito de competências essenciais ganhou destaque no contexto empresarial e no mundo acadêmico com a publicação do artigo 'The Core Competence of the Organization', de Prahalad e Hamel, em 1990. De acordo com estes autores, as competências essenciais correspondem ao aprendizado coletivo na organização, especialmente como coordenar as diversas habilidades de produção e integrar as múltiplas correntes de tecnologias.

Entretanto, o conceito de competências essenciais não diz respeito exclusivamente aos aspectos tecnológicos. De acordo com estes autores, o conceito de competências essenciais também está associado à organização do trabalho e à entrega de valor. Fleury e Fleury (2003) mencionam que as competências essenciais não estão estritamente relacionadas à tecnologia, mas podem estar localizadas em qualquer função administrativa. Além disso, para desenvolver competência essencial de longo prazo, a companhia necessita de um processo sistemático de aprendizagem e inovação organizacional.

De acordo com Johnson et al. (2007), os recursos são importantes, mas o que uma organização faz, como ela emprega seus recursos e dispõe deles, é tão importante quanto os recursos que ela possui. Não faz sentido ter equipamentos de última geração ou conhecimento valioso ou um marca valiosa se isso não for usado de forma efetiva. A eficiência e eficácia dos recursos físicos ou financeiros, ou das pessoas em uma organização, não dependem apenas de sua existência, mas principalmente da forma como são gerenciados, da cooperação entre as pessoas, da sua capacidade de adaptação e inovação, da relação com clientes e 
fornecedores e da experiência e aprendizado sobre aquilo que funciona e o que não funciona corretamente. Ou seja, para entender a capacidade estratégica de uma empresa, a ênfase não está apenas nos recursos existentes, mas sim na forma como estes são utilizados.

Para Ritzman e Krajewski (2004), uma boa habilidade gerencial isoladamente pode não ser suficiente para lidar com as mudanças ambientais. A estratégia corporativa é que precisa lidar com elas. As empresas obtêm sucesso tirando vantagem daquilo que fazem particularmente bem, isto é, dos pontos fortes exclusivos da organização. Para estes autores, competências essenciais são os recursos exclusivos e pontos fortes da alta administração que uma organização considera quando formula suas estratégias. Elas refletem o conhecimento coletivo da organização, especialmente os relativos ao modo de coordenar os diversos processos e integrar as múltiplas tecnologias existentes.

Dependendo do tipo de produto/ mercado no qual a empresa atua, uma função empresarial será mais importante e 'terá mais poder' do que as outras, e exercerá um papel de coordenação geral entre as funções. Fleury e Fleury (2003) afirmam que para a realização da estratégia da empresa, as competências acumuladas nesta função crítica constituem a 'competência essencial da empresa'. Em outras palavras, ela (a função crítica - competência essencial) é a mais importante para a realização da estratégia competitiva da empresa e as demais funções são de apoio.

Prahalad e Hamel (1990) afirmam que as competências essenciais são seus recursos críticos, sendo que a alta gerência deve assegurar que as funções portadoras dessa competência não sejam mantidas presas a um negócio em particular. Ainda de acordo com estes autores, as competências essenciais não diminuem com o uso. Ao contrário dos recursos físicos, que se deterioram com o tempo, as competências desenvolvem-se à medida que são aplicadas e compartilhadas.

Nota-se, através das discussões acima, a existência de uma correlação entre competências essenciais, recursos e capacitações. De acordo com Hoskisson et al. (2004), as competências essenciais são os recursos e capacitações que servem como a fonte de vantagem competitiva de uma firma sobre seus competidores. Elas distinguem a empresa em termos competitivos e refletem sua personalidade. As 
competências essenciais emergem ao longo do tempo através de um processo organizacional de acumulação de aprendizado sobre a melhor utilização dos recursos e capacitações da empresa. Em outras palavras, segundo os autores, as competências essenciais seriam as atividades que a empresa desempenha especialmente bem quando comparada com seus principais competidores.

Fitzroy e Hulbert (2005) também estabelecem a relação entre recursos e competências essenciais. Segundo estes autores, a perspectiva baseada em recursos (visão baseada em recursos) enxerga a firma como uma combinação única de recursos e competências que são à base de sua estratégia e sucesso. Os recursos são os fundamentos mais básicos da firma em termos financeiros e físicos, bem como os atributos intangíveis da firma. Já as competências se referem à habilidade da firma em combinar e integrar estes recursos.

Autores, como Besanko et al. (2004), chegam ao ponto de não fazer distinção entre capacitações e competências essenciais. Para estes autores, capacitações são atividades que a firma faz especialmente bem quando comparado com outras firmas. Outros termos para este conceito seriam competências distintivas e competências essenciais.

Sob este ponto de vista, as diferenças entre o sucesso de diferentes firmas podem ocorrer por conta dos diferentes recursos e competências que as mesmas possuem. Isto poderia explicar o porquê empresas do mesmo setor apresentam desempenhos diferentes (independentemente do grau de atratividade do setor).

Craig e Grant (1999) afirmam que, se uma empresa possui recursos e capacidades superiores aos de seus concorrentes e adota uma estratégia que utiliza esses recursos e capacidades de maneira eficaz, ela poderá criar uma vantagem competitiva. Mas, em termos de capacidade de tirar proveito dessa posição de vantagem competitiva, uma questão decisiva é o período durante o qual a empresa poderá manter sua vantagem. Para que essa vantagem competitiva seja sustentável é necessário que estes recursos e capacitações possuam três características principais: durabilidade, capacidade de transferência e capacidade de reprodução.

A partir da discussão feita à questão que seu apresenta é: como então identificar essas competências essenciais na empresa? Para Hoskisson et al. (2004), existem duas ferramentas que ajudam nesta tarefa. A primeira ferramenta consiste na aplicação de quatro critérios específicos de classificação de vantagem 
competitiva em sustentável ou não, e que as empresas devem usar para determinar se seus recursos e capacitações são, ou têm potencial para ser tornarem competências essenciais. A segunda ferramenta consiste na análise da cadeia de valor da empresa para selecionar as competências criadoras de valor, as quais devem ser mantidas, melhoradas ou desenvolvidas, bem como selecionar aquelas que devem ou podem ser terceirizadas.

A aplicação da primeira ferramenta (uso de quatro critérios específicos de vantagem competitiva sustentável) inicia-se com a análise que está sintetizada na figura 1.

Figura 1 - Competência Essencial como uma Capacitação Estratégica

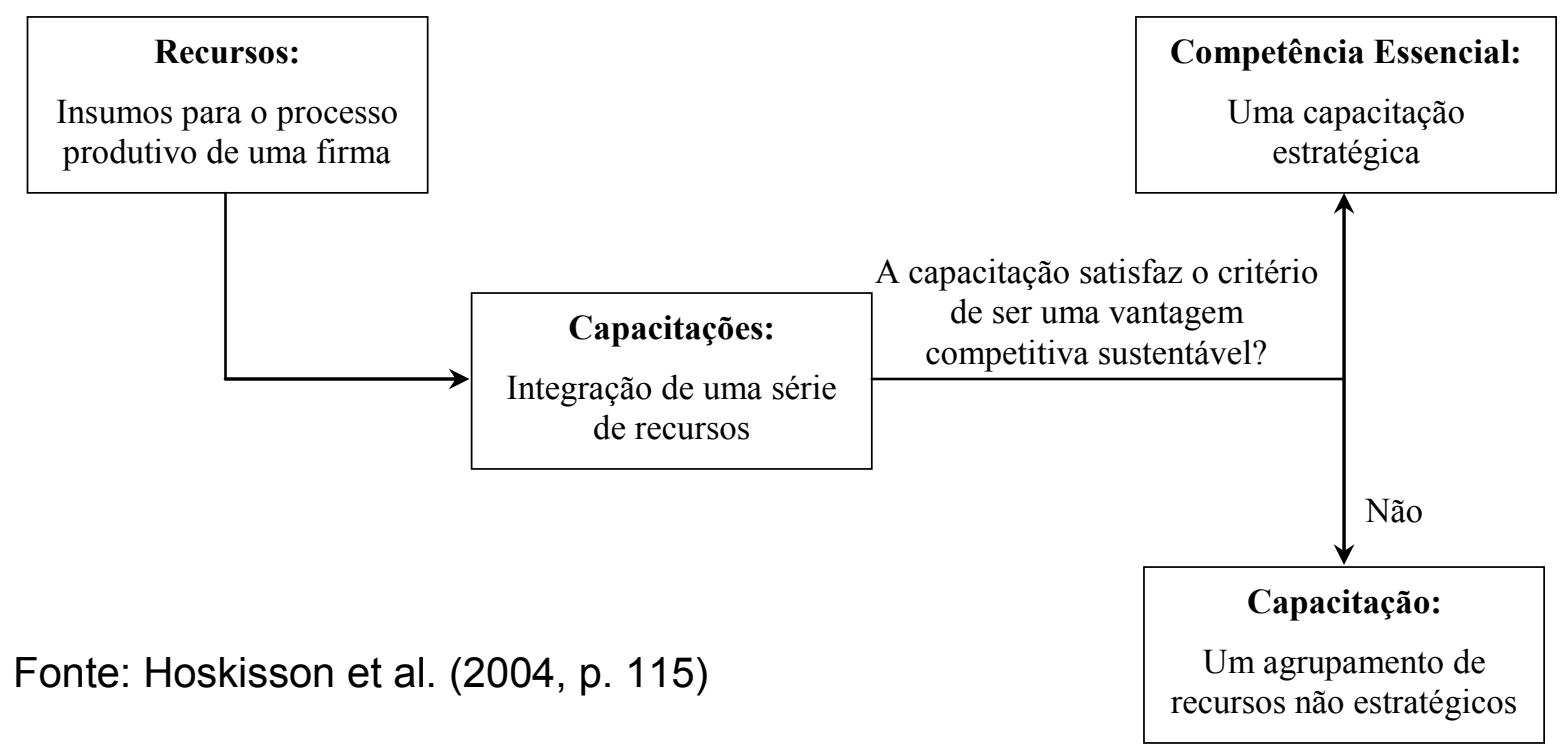

Resumidamente, tem-se que os recursos são insumos das capacitações que, por sua vez podem ou não serem fontes de vantagens competitivas sustentáveis. Caso isso seja verdadeira, ou seja, a capacitação em questão é uma fonte de vantagem competitiva sustentável, então ela é uma capacitação estratégica e pode ser denominada competência essencial. Caso isso não ocorra, a capacitação em questão é apenas um agrupamento de recursos não estratégicos.

Como determinar se a capacitação é de fato uma fonte de vantagem competitiva sustentável?

A visão baseada em recursos coloca que a resposta a esta questão baseia-se na posse de certos recursos básicos, recursos estes que possuem características como ‘valor', 'barreiras para duplicação' e 'capacidade de apropriação'. Hoskisson et 
al. (2004) sugerem então, baseado nessas colocações, a aplicação dos quatro critérios de determinação. Segundo estes autores, para a capacitação ser considerada uma vantagem competitiva sustentável, ela deverá preencher os quatro critérios, ou seja, deverá ser: (i) geradora de valor; (ii) rara; (iii) difícil de ser imitada; e (iv) não substituível. Por consequência, capacitações que atendem os quatro critérios são consideradas competências essenciais.

De todo modo, como nem sempre uma competência essencial preenche claramente os quatro critérios acima descritos, os mesmos autores realizaram uma combinação destes critérios de forma a determinar se determinada capacitação leva a uma vantagem competitiva sustentável ou temporária, conforme pode ser observado pelo quadro 1. Nessa direção o quadro 1 apresenta uma representação do uso dos quatro critérios propostos por Hoskisson et al. (2004), que nortearam a conceituação de competências essenciais na presente pesquisa.

Quadro 1 - Resultados das combinações dos critérios para a obtenção da Vantagem Competitiva Sustentável

\begin{tabular}{|c|c|c|c|c|c|}
\hline $\begin{array}{c}\text { O recurso } \\
\text { ou } \\
\text { capacitação } \\
\text { é gerador } \\
\text { de valor? }\end{array}$ & $\begin{array}{c}\text { O recurso } \\
\text { ou } \\
\text { capacitação } \\
\text { é escasso? }\end{array}$ & $\begin{array}{c}\text { Este recurso } \\
\text { ou } \\
\text { capacitação é } \\
\text { difícil ou caro } \\
\text { de ser } \\
\text { imitado? }\end{array}$ & $\begin{array}{c}\text { Este recurso } \\
\text { ou } \\
\text { capacitação é } \\
\text { insubstituível? }\end{array}$ & $\begin{array}{c}\text { Consequências } \\
\text { competitivas }\end{array}$ & $\begin{array}{c}\text { Implicações } \\
\text { no } \\
\text { desempenho } \\
\text { da empresa }\end{array}$ \\
\hline Não & Não & Não & Não & $\begin{array}{c}\text { Desvantagem } \\
\text { competitiva }\end{array}$ & $\begin{array}{c}\text { Retornos } \\
\text { abaixo da } \\
\text { média }\end{array}$ \\
\hline Sim & Não & Não & Sim/Não & $\begin{array}{c}\text { Retornos } \\
\text { Pampetitiva }\end{array}$ & $\begin{array}{c}\text { semelhantes } \\
\text { aos dos } \\
\text { competidores }\end{array}$ \\
\hline Sim & Sim & Não & Sim/Não & $\begin{array}{c}\text { Vantagem } \\
\text { competitiva } \\
\text { temporária }\end{array}$ & $\begin{array}{c}\text { Retornos } \\
\text { ligeiramente } \\
\text { acima da } \\
\text { média }\end{array}$ \\
\hline Sim & Sim & Sim & Sim & $\begin{array}{c}\text { Vantagem } \\
\text { competitiva } \\
\text { sustentável }\end{array}$ & $\begin{array}{c}\text { Retornos } \\
\text { acima da } \\
\text { média }\end{array}$ \\
\hline
\end{tabular}

Fonte: Hoskisson et al. (2004, p. 118)

\section{CONTEXTUALIZAÇÃO METODOLÓGICA}

De acordo com a teoria da visão baseada em recurso as empresas são uma coleção heterogênea de recursos que resultam em desempenhos de mercado distintos. Para Wilk e Fensterseifer (2003) o uso desta teoria ajuda a entender e 
explicar porque algumas empresas apresentam desempenho melhor que outras, enquanto o ambiente competitivo sem mantém o mesmo para todas.

Levando isso em consideração, a pesquisa original, base do presente artigo partiu do seguinte pressuposto básico: os frigoríficos brasileiros exportadores de carne bovina possuem competências essenciais que os tornam competitivos para exportar, o que os diferencia dos frigoríficos que atendem somente o mercado interno.

Como a presente pesquisa procurou contextualizar fenômenos e não quantificá-los, e considerando o pequeno universo de empresas pesquisadas, o que confere a possibilidade de maior aprofundamento na análise destas empresas, optou-se pela escolha do estudo multicaso como método de pesquisa e pelo uso de amostragem por julgamento. Neste processo as empresas participantes são selecionadas segundo um critério de julgamento do pesquisador, tendo como base o que se acredita que o elemento selecionado possa fornecer ao estudo (WOLLENHAUPT, 2004).

Os critérios estabelecidos para a determinação da amostra foram:

a. Empresas que abatem bovinos e que sejam processadoras de carne bovina;

b. Empresas que estejam classificadas entre os 10 maiores frigoríficos de carne bovina no Brasil;

c. Empresas de perfil exportador, preferencialmente associadas à ABIEC (Associação Brasileira das Indústrias Exportadoras de Carne);

d. Empresas que tenham plantas industriais espalhadas pelos principais estados produtores de carne bovina no Brasil;

e. Concordância da empresa em participar da pesquisa.

A pesquisa de campo foi realizada com três das principais empresas processadoras de carne bovina no Brasil (frigoríficos), que se situam entre os 7 maiores exportadores de carne bovina do país. Estas empresas possuem plantas industriais espalhadas pelos principais estados produtores de carne bovina no Brasil, bem como estão avançando nos seus processos de internacionalização, algumas com a aquisição de plantas industriais nos principais países produtores de carne bovina no mundo. Informações adicionais a respeito das empresas participantes não 
são aqui fornecidas de forma a preservar a confidencialidade acordada entre pesquisadores e empresas.

Trata-se de uma quantidade de estudos de casos apropriada, levando-se em consideração que são poucos os frigoríficos de carne bovina habilitados a exportar para a União Europeia e observa-se uma concentração nas exportações por parte desses frigoríficos.

O referencial teórico que engloba os assuntos 'recursos', 'capacitações' e 'competências essenciais' foi desenvolvido através de pesquisa bibliográfica. As informações referentes à cadeia da carne bovina no Brasil foram desenvolvidas com base em dados secundários. Já os dados primários foram obtidos através das entrevistas com as empresas estudadas. A coleta de dados foi realizada através de entrevistas presenciais com os executivos das empresas pesquisas, sendo que o questionário estruturado que norteou as entrevistas foi elaborado com base no arcabouço teórico discutido neste artigo. Posteriormente estes dados foram analisados e seus resultados discutidos. Para tanto relatórios individuais de cada caso foram gerados, padrões de dados foram extraídos e comparados aos presentes na literatura utilizada, fornecendo base para as discussões realizadas.

Dados secundários também foram utilizados na elaboração dos estudos de caso, principalmente com o intuito de permitir uma melhor contextualização das empresas estudadas. Desta forma, foram utilizados dados públicos obtidos nos websites das empresas, bem como jornais e revistas especializadas em agronegócios e cadeia da carne bovina.

O ponto de partida para a determinação das competências essenciais foi o mapeamento dos principais recursos e capacitações existentes nos frigoríficos analisados. A análise e interpretação dos dados utilizados para a determinação das competências essenciais que impactam a comercialização da carne bovina brasileira no mercado europeu foi baseada na combinação de conceitos de diversos autores, como explicitado a seguir.

A etapa inicial foi a identificação dos recursos presentes nos frigoríficos analisados e sua classificação em recursos em tangíveis e intangíveis, de acordo com Hoskisson et al. (2004, p. 109). Além disso, também foi utilizada a classificação proposta por Barney (1991); Grant (1991 apud HOSKISSON et al. 2004, p. 109) que agrupa os recursos tangíveis em financeiros, organizacionais, físicos e tecnológicos. 
Já recursos intangíveis são agrupados em recursos humanos, inovadores e de reputação.

Com base na identificação e classificação dos recursos dos frigoríficos estudados, o segundo passo foi a identificação de suas capacitações. Uma capacitação é uma série de recursos integrados. A classificação das capacitações se utilizou dos conceitos de Dranove e Marciano (2005) que qualificam as capacitações como "verbos". Sob esta ótica, as capacitações demonstram o que as empresas fazem com seus recursos.

A determinação das capacitações também seguiu Craig e Grant (1999) e Hoskisson et al. (2004), que afirmam que os recursos são os patrimônios específicos da empresa: bens de capital, qualificação dos funcionários, patentes, marcas e similares. Já as capacitações são o que a empresa pode fazer, ou seja, o resultado dos recursos trabalhando em conjunto para realizar tarefas produtivas.

Desta forma, os recursos mapeados na pesquisa se combinam de forma a gerar diferentes tarefas produtivas, ou diferentes capacitações. Estes recursos e capacitações são a base das competências essenciais encontradas nos frigoríficos analisados, cuja determinação será descrita no passo seguinte.

O terceiro passo, de extrema importância, foi analisar quais destes recursos e capacitações geram vantagens competitivas para os frigoríficos em questão, tornando-se portanto competências essenciais. Esta análise seguiu os conceitos de Lasserre (2003), que menciona a intrínseca relação entre capacitações e vantagens competitivas.

A classificação das capacitações em competências essenciais seguiu também os conceitos de Hoskisson et al. (2004). Segundo estes autores, se a capacitação satisfaz o critério de ser uma fonte de vantagem competitiva, então ela é uma capacitação estratégica, logo, uma competência essencial. Entretanto, se a capacitação não satisfaz o critério de ser uma fonte de vantagem competitiva para a empresa, então ela é apenas um agrupamento de recursos não estratégicos. Com base nestes conceitos, foram identificadas as competências essenciais individuais dos frigoríficos analisados na pesquisa. As competências essenciais existentes nestes frigoríficos afetam em diferentes níveis a sua capacidade de exportação.

A definição da capacitação como fonte de vantagem competitiva (logo, competência essencial) seguiu os quatro critérios de Hoskisson et al. (2004), que 
definem que para a capacitação ser considerada uma vantagem competitiva sustentável, ela deverá preencher quatro critérios, ou seja, a capacitação deverá ser: (i) geradora de valor; (ii) rara (escassa); (iii) cara ou difícil de ser imitada; e (iv) não substituível.

Desta forma, a competência essencial que preenche os quatro critérios é considerada uma fonte de vantagem sustentável, cuja implicação no desempenho da empresa é proporcionar à mesma retornos acima da média do setor. Infere-se, portanto, que esta é uma competência essencial sustentável. Já a competência essencial que é fácil (ou barata) de ser imitada, leva a uma vantagem competitiva temporária, com retornos ligeiramente acima da média. Neste caso, infere-se que se trata de uma competência essencial temporária.

\section{COMPETÊNCIAS ESSENCIAIS: ANÁLISE DOS RESULTADOS}

Como colocado no item 3 , o ponto de partida para a determinação das competências essenciais foi o mapeamento dos principais recursos e capacitações presentes nos frigoríficos analisados.

Desta forma, a pesquisa de campo identificou 25 recursos, que são os insumos básicos para o processo produtivo ou estão à disposição dos frigoríficos analisados, sendo que 18 deles foram classificados como tangíveis e 7 intangíveis.

A partir dos 25 recursos identificados na pesquisa, foram mapeadas 23 capacitações. Uma capacitação foi definida como uma série de recursos integrados, ou o resultado dos recursos trabalhando em conjunto para realizar tarefas produtivas.

Desta forma, os 25 recursos combinaram-se de forma a gerar 23 tarefas produtivas, ou capacitações diferentes. Alguns recursos, como mão de obra (nas linhas de abate e desossa), equipamentos e a própria linha de abate e desossa geram uma única capacitação, no caso a capacitação "processo de abate e desossa". Outros recursos, como "marca" e "percepção de qualidade" geram capacitações muito próximas, mas que possuem importância no contexto da análise das competências essenciais dos frigoríficos estudados, sendo, portanto, tratadas isoladamente. 
Os principais recursos e capacitações intangíveis e tangíveis presentes nos frigoríficos analisados estão apresentados respectivamente nos quadro 2 e 3, que foram elaborados pelos autores com os dados da pesquisa e baseado nas discussões de Barney (1991); Grant (1991apud HOSKISSON et al., 2004, p. 109).

Quadro 2 - Recursos e Capacitações Intangíveis presentes no conjunto dos Frigoríficos Estudados
\begin{tabular}{|l|l|l|}
\hline \multicolumn{1}{|c|}{ Recurso } & \multicolumn{1}{|c|}{ Descrição } & \multicolumn{1}{c|}{ Capacitação } \\
\hline Humano & Conhecimento & $\begin{array}{l}\text { Conhecimento do mercado europeu da } \\
\text { carne bovina }\end{array}$ \\
\hline Humano & Capacitações gerenciais & Gestão profissionalizada \\
\hline Inovador & $\begin{array}{l}\text { Ideias / capacitações científicas / } \\
\text { capacidade em inovar }\end{array}$ & $\begin{array}{l}\text { Pequena importância na indústria da } \\
\text { carne bovina (principalmente in natura) }\end{array}$ \\
\hline Reputacional & Reputação com consumidores & Tradição \\
\hline Reputacional & Marca & $\begin{array}{l}\text { Oferecimento de bons produtos } \\
\text { aumentando confiança do cliente }\end{array}$ \\
\hline Reputacional & $\begin{array}{l}\text { Percepção de qualidade, durabilidade e } \\
\text { confiança nos produtos }\end{array}$ & $\begin{array}{l}\text { Oferecimento de bons produtos } \\
\text { aumentando confiança do cliente }\end{array}$ \\
\hline Reputacional & $\begin{array}{l}\text { Reputação com fornecedores, de forma } \\
\text { a criar interações e relações } \\
\text { mutuamente eficientes e eficazes }\end{array}$ & $\begin{array}{l}\text { Capacidade de adquirir animais } \\
\text { "padrão- exportação" com certa } \\
\text { regularidade }\end{array}$ \\
\hline
\end{tabular}

É importante ressaltar que os recursos e capacitações mapeados e definidos a partir da pesquisa de campo são comuns, em maior ou menor escala, a todos os frigoríficos analisados e foi o ponto de partida para a determinação das competências essenciais de cada frigorífico.

O passo seguinte foi analisar quais destes recursos e capacitações geram vantagens competitivas para os frigoríficos analisados. Esta análise foi realizada de maneira individualizada para cada frigorífico nos estudos de caso e posteriormente agrupadas.

Deste modo, vale a ressalva de que as competências essenciais de cada frigorífico foram agrupadas de forma a determinar quais são as competências essenciais do conjunto dos frigoríficos estudados. Desta forma, os quadros e figuras apresentadas representam a somatória das competências essenciais de todos os frigoríficos estudados. 
Quadro 3 - Recursos e Capacitações Tangíveis presentes no Conjunto dos Frigoríficos Estudados

\begin{tabular}{|c|c|c|}
\hline Recurso & Descrição & Capacitação \\
\hline Financeiro & Capacidade da firma se financiar & $\begin{array}{l}\text { Acesso a mercado de capitais } \\
\text { (nacional e internacional) / estruturação } \\
\text { de operações de Eurobonds e abertura } \\
\text { de capital }\end{array}$ \\
\hline Organizacional & $\begin{array}{l}\text { A estrutura formal dos relatórios da } \\
\text { empresa, que inclui seus sistemas } \\
\text { formais de planejamento, controle e } \\
\text { coordenação }\end{array}$ & Governança corporativa \\
\hline Organizacional & Opinião dos funcionários & Gestão participativa \\
\hline Organizacional & $\begin{array}{l}\text { Empresas concorrentes, distribuidores } \\
\text { de carne bovina }\end{array}$ & $\begin{array}{l}\text { Estratégia de crescimento via fusões \& } \\
\text { aquisições }\end{array}$ \\
\hline Organizacional & $\begin{array}{l}\text { Empresas concorrentes, distribuidores } \\
\text { de carne bovina (internacionais) }\end{array}$ & Internacionalização \\
\hline Organizacional & $\begin{array}{l}\text { Sistemas de qualidade (HACCP, BPF, } \\
\text { ISO) }\end{array}$ & Controle de processos \\
\hline Organizacional & $\begin{array}{l}\text { Certificação pública para exportação } \\
\text { (inclui rastreabilidade) }\end{array}$ & $\begin{array}{l}\text { Habilitação para exportação para canal } \\
\text { de distribuição genérico }\end{array}$ \\
\hline Organizacional & $\begin{array}{l}\text { Certificações privadas (ex.: Eurepgap, } \\
\text { BRC, etc.) }\end{array}$ & $\begin{array}{l}\text { Habilitação para exportação para canal } \\
\text { de distribuição bastante específico }\end{array}$ \\
\hline Físico & Plantas industriais & Processo de abate e desossa \\
\hline Físico & Equipamentos de abate e desossa & Processo de abate e desossa \\
\hline Físico & $\begin{array}{l}\text { Mão-de-obra - linhas de abate e } \\
\text { desossa }\end{array}$ & Processo de abate e desossa \\
\hline Físico & Câmaras frigoríficas & $\begin{array}{l}\text { Processo de armazenagem da carne } \\
\text { bovina }\end{array}$ \\
\hline Físico & Matéria-prima & $\begin{array}{l}\text { Capacidade de adquirir animais } \\
\text { "padrão-exportação" com certa } \\
\text { regularidade }\end{array}$ \\
\hline Físico & Localização & $\begin{array}{l}\text { Acesso à matéria-prima (principais } \\
\text { praças pecuárias) / diversificação } \\
\text { geográfica }\end{array}$ \\
\hline Físico & Recursos logísticos em geral & $\begin{array}{l}\text { Transportar eficientemente os produtos } \\
\text { da empresa }\end{array}$ \\
\hline Físico & Escala de produção & Operar em grande escala de produção \\
\hline Físico & $\begin{array}{l}\text { Integração entre produção de carne in } \\
\text { natura e carne industrializada }\end{array}$ & $\begin{array}{l}\text { Agregar valor à carne do dianteiro } \\
\text { bovino e criar novos canais de } \\
\text { distribuição para este produto }\end{array}$ \\
\hline Tecnológico & $\begin{array}{l}\text { "Estoque" de tecnologia como } \\
\text { patentes, trademarks (marcas } \\
\text { registradas) e copyrights (direitos } \\
\text { autorais) }\end{array}$ & $\begin{array}{l}\text { Produtos com alto uso de tecnologia de } \\
\text { processamento }\end{array}$ \\
\hline
\end{tabular}

Foram identificadas 19 competências essenciais no conjunto dos frigoríficos analisados na pesquisa, que compõem as competências essenciais deste pequeno, porém representativo, grupo de frigoríficos brasileiros, grandes exportadores de carne bovina.

A figura 2 sintetiza este conjunto de competências essenciais, partindo da apresentação da relação de todos os recursos presentes, tangíveis e intangíveis, das respectivas capacitações e finalizando com a relação das competências 
essenciais existentes no grupo pesquisado. A figura 2 foi elaborada com os dados da pesquisa e baseada nas discussões de Barney (1991); Grant (1991 apud HOSKISSON et. al., 2004, p. 109), Dranove E Marciano (2005, p. 51), Lasserre (2003, p. 47) e Hoskisson et al. (2004, p. 115). 
Figura 2 - Competências Essenciais presentes no Conjunto dos Frigoríficos Estudados

\section{Recursos}

1) Financeiros: Capacidade da firma se financiar

2) Estrutura formal de relatórios

3) Opinião dos funcionários

4) Empresas concorrentes / distribuidores de carne bovina

5) Empresas concorrentes / distribuidores de carne bovina (internacionais)

6) Sistemas de qualidade (HACCP, por exemplo)

7) Certificação pública para exportação

8) Certificações privadas (ex: Eurepgap)

9) Plantas industriais

10) Equipamentos de abate e desossa

11) Mão-de-obra - abate e desossa

12) Câmaras frigoríficas

13) Matéria-prima (gado bovino para abate)

14) Localização

15) Recursos logísticos

16) Escala de produção

17) Integração com carne in natura e carne industrializada

18) Estoque de tecnologia (patentes, marcas registradas)

19) Conhecimento

20) Capacitações gerenciais

21) Inovação

22) Reputação com consumidores

23) Marca

24) Percepção de qualidade / durabilidade /

\section{Capacitações}

1) Acesso a recursos financeiros diferenciados (mercado de capitais, possibilidade de abertura de capital)

2) Governança corporativa

3) Gestão participativa

4) Estratégia de crescimento via fusões \& aquisições

5) Internacionalização

6) Sistemas de qualidade / controle de processos

7) Certificação - exportação canal genérico

8) Certificação - exportação canal específico

9) Processo de abate e desossa

10) Processo de armazenagem de carne bovina

11) Capacidade de adquirir animais "padrão-

exportação" com certa regularidade

12) Diversificação geográfica (hedge sanitário e acesso à matéria-prima)

13) Transportar eficientemente os produtos da empresa

14) Operar em grande escala de produção

15) Agregar valor à carne do dianteiro bovino e

criar novos canais de distribuição para o produto

16) Produzir produtos tecnológicos

17) Conhecimento do mercado europeu da carne bovina

18) Gestão profissionalizada

19) Produção de produtos inovadores

20) Tradição

21) Marcas: credibilidade / bons produtos

confiança do cliente

22) Percepção de qualidade: qualidade

credibilidade / confiança dos clientes

23) Relacionamento com fornecedores: capacidade de adquirir animais padrãoexportaçãoA fonte de

\section{Competências Essenciais}

1) Acesso a recursos financeiros diferenciados (mercado de capitais, possibilidade de abertura de capital)

2) Governança corporativa

3) Gestão participativa

4) Estratégia de crescimento via fusões \&

aquisições

5) Internacionalização

6) Certificação - exportação canal genérico

7) Certificação - exportação canal específico

8) Processo de armazenagem de carne bovina

9) Capacidade de adquirir animais "padrão-

exportação" com certa regularidade

10) Diversificação geográfica (hedge sanitário e

acesso à matéria-prima)

11) Transportar eficientemente os produtos da empresa

12) Operar em grande escala de produção

13) Agregação de valor à carne do dianteiro bovino e criar novos canais de distribuição para o produto

14) Conhecimento do mercado europeu da carne bovina

15) Gestão profissionalizada

16) Tradição

17) Marcas: credibilidade / bons produtos / confiança do cliente

18) Percepção de qualidade: qualidade credibilidade / confiança dos clientes

19) Relacionamento com fornecedores: capacidade de adquirir animais padrão-exportação

Capacitações 6, 9,16 e 19 não são claramente fontes de vantagens competitivas para os frigoríficos pesquisados, logo são agrupamentos de recursos não estratégicosSim

Revista Produção Online, Florianópolis, SC, v.13, n. 1, p. 180-207, jan./mar. 2013. 
Cabe destacar que tais competências afetam em diferentes graus a capacidade de exportação deste conjunto de frigoríficos, ou seja, a importância relativa das mesmas não é igual para todos eles. Em alguns casos, determinada(s) competência(s) detém um peso mais significativo do que em outro(s), mas de forma geral todas elas podem ser identificadas nos casos estudados. Por fim, visto que nem todas as competências essenciais são sustentáveis, elaborou-se a figura 3, que apresenta quais das competências essenciais do conjunto de frigoríficos estudados são sustentáveis e quais são temporárias.

Figura 3 - Competências Essenciais Sustentáveis e Temporárias do Conjunto de Frigoríficos Analisados

\section{Frigoríficos Estudados - \\ Competências Essenciais}

1) Acesso a recursos financeiros diferenciados (mercado de capitais, possibilidade de abertura de capital)

2) Governança corporativa

3) Gestão participativa

4) Estratégia de crescimento via fusões \& aquisições

5) Internacionalização

6) Certificação - exportação canal genérico

7) Certificação - exportação canal específico

8) Processo de armazenagem de carne bovina

9) Capacidade de adquirir animais padrão-exportação com certa regularidade

10) Diversificação geográfica (hedge sanitário)

11) Transportar eficientemente os produtos da empresa

12) Operar em grande escala de produção

13) Agregação de valor à carne do dianteiro bovino (industrialização)

14) Conhecimento do mercado europeu de carne bovina

15) Gestão profissionalizada

16) Tradição

17) Marcas: oferecimento de bons produtos / credibilidade

18) Percepção de qualidade: oferecimento de bons produtos / qualidade

19) Relacionamento com

fornecedores: capacidade de adquirir animais padrão-exportação com regularidade
Competências Essenciais Sustentáveis

1) Acesso a recursos financeiros diferenciados

2) Estratégia de crescimento via fusões $\&$ aquisições

3) Internacionalização

4) Certificação - canal genérico

5) Certificação - canal específico

6) Operar em grande escala de produção

7) Conhecimento do mercado europeu de carne bovina

8) Tradição

9) Marcas: oferecimento de bons produtos / credibilidade

10) Percepção de qualidade: oferecimento de bons produtos / qualidade

\section{Competências Essenciais} Temporárias

1) Governança corporativa

2) Gestão participativa

3) Armazenagem

4) Aquisição de animais padrãoexportação

5) Diversificação geográfica

6) Transportar eficientemente os produtos da empresa

7) Agregação de valor à carne do dianteiro bovino

(industrialização)

8) Gestão profissionalizada

9) Relacionamento com

fornecedores: aquisição animais padrão-exportação com

regularidade

Revista Produção Online, Florianópolis, SC, v.13, n. 1, p. 180-207, jan./mar. 2013. 
A figura 3 foi elaborada com os dados da pesquisa e baseada nas discussões de Barney (1991); Grant (1991 apud HOSKISSON et al., 2004, p. 109), Dranove e Marciano (2005, p. 51), Lasserre (2003, p. 47) e Hoskisson et al. (2004, p. 115).

De acordo com a figura 3 , dentre as 19 competências essenciais do conjunto de frigoríficos analisados na pesquisa, 10 competências são sustentáveis, enquanto que 9 competências são temporárias, por serem relativamente fáceis ou baratas de serem imitadas.

Já a figura 4 apresenta o número de recursos, capacitações e competências essenciais, sustentáveis e temporárias, presentes no conjunto dos frigoríficos analisados. Esta figura dá destaque à presença dos recursos e capacitações intangíveis na determinação das competências essenciais dos frigoríficos da amostra, principalmente no que se refere às competências essenciais sustentáveis.

Figura 4 - Síntese do número de Recursos, Capacitações e Competências Essenciais, Sustentáveis e Temporárias, presentes no Conjunto de Frigoríficos Analisados.

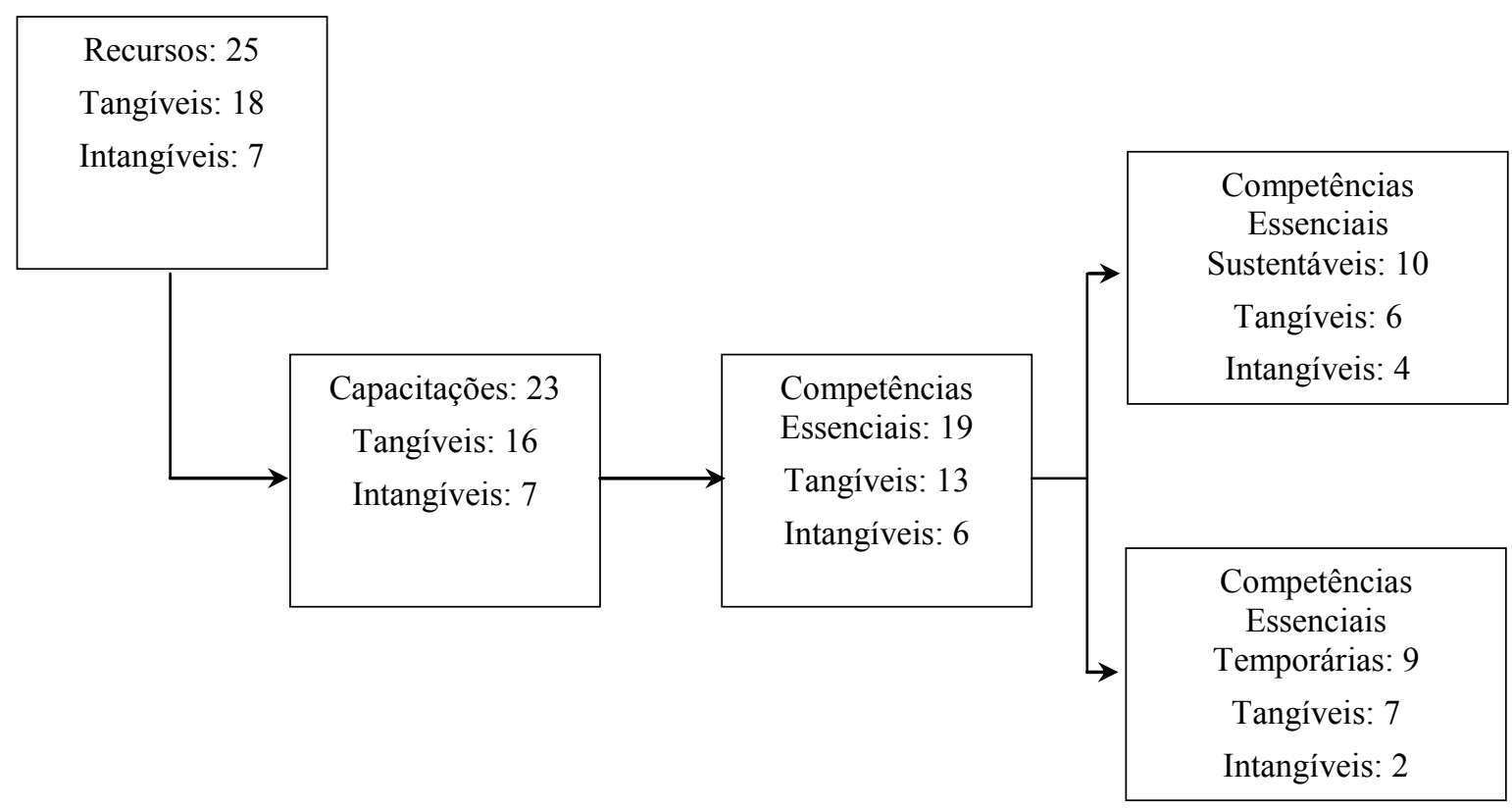

Desta forma, apesar do grande número de competências essenciais baseadas em recursos e capacitações tangíveis, vale a pena destacar a importância das competências essenciais que possuem origem em recursos e capacitações intangíveis existentes nas exportações de carne bovina para a Europa. Tais competências essenciais baseadas em recursos e capacitações intangíveis são: conhecimento do mercado, tradição, reputação, marcas e qualidade da carne. Estas 
competências possuem componentes que impactam os relacionamentos entre os agentes e permitem aos frigoríficos analisados estabelecerem paulatinamente relações de longo prazo com seus clientes no mercado europeu.

Desta forma, tem-se uma situação em que as competências essenciais baseadas em recursos e capacitações tangíveis "suportam" aquelas baseadas em recursos intangíveis. Em outras palavras, as "competências tangíveis" garantem a oferta adequada de carne bovina em padrões de qualidade específicos para a exportação, mas são as "competências intangíveis" que estreitam o relacionamento entre as partes no canal de distribuição, possibilitando a criação de vantagens competitivas sustentáveis.

\section{CONSIDERAÇÕES FINAIS}

Após coletar os dados, o pesquisador deverá analisá-los e interpretá-los. A interpretação visa à reflexão e à explicação; busca apresentar os resultados em um contexto mais abrangente, interligá-los, compará-los e avaliá-los para solucionar o problema. De acordo com Lakatos E Marconi (2004) e Barros E Lehfeld (2000), na interpretação dos dados, dois aspectos são importantes:

a. Construção de tipos, modelos e esquemas através do uso dos conceitos teóricos, relação com as variáveis quantificadas e realização de comparações pertinentes; e

b. Ligação com a teoria - pressupõe uma definição metodológica e teórica do pesquisador em termos de seleção entre as alternativas disponíveis da interpretação da realidade.

Os resultados apresentados no item 4 demonstram que esta pesquisa obteve resultados que apontam a existência de competências essenciais nas empresas analisadas, que alavancam a capacidade destas para a exportação de seus produtos.

Com relação ao objetivo do artigo, apresentar as competências essenciais presentes nos frigoríficos brasileiros exportadores de carne in natura para Europa, e classifica-las em sustentáveis e temporárias, os resultados apresentados no item 4 demonstram que o mesmo foi atendido. Destacou-se que existem competências essenciais de natureza tangível, como escala de abate, capacidade de 
armazenamento, localização etc. Porém um resultado considerado muito interessante é que as principais competências essenciais dos frigoríficos analisados dizem respeito a recursos e capacitações intangíveis, como tradição, conhecimento de mercado, qualidade da carne etc.

Os resultados obtidos nesta pesquisa vão de encontro aos apresentados por Dal-Soto, Paiva e Souza (2007) que, utilizando o conceito de competências essenciais como base teórica para a interpretação dos dados, mostraram que a internacionalização de empresas de médio porte da cadeia coureiro-calçadista da região do Vale dos Sinos, apoia-se em uma combinação de recursos associados a competências, entre elas competências associadas a capacidade de entender os mercados e a habilidade de agregar parceiros. Cabe ressaltar que estes autores usam o termo competências organizacionais como sinônimo de competências essenciais.

De todo modo, mesmo tendo como certo que a competição atual ocorre em torno das competências, base do referencial teórico, e que estudos nesta direção são considerados importantes para que os gestores avaliem a capacidade de inserção competitiva das empresas brasileiras no mercado externo, algumas considerações quanto à classificação de competências essenciais presentes nos frigoríficos analisados devem ser colocadas.

A primeira consideração diz respeito ao impacto destas competências essenciais na criação de vantagens competitivas sustentáveis de um frigorífico em relação ao outro. Em outras palavras, existem competências essenciais com maior impacto competitivo do que outras e com diferentes impactos entre os frigoríficos, sendo que a presente pesquisa não se preocupou em determiná-los e muito menos explicitá-los. A resposta a estas ponderações não foi objeto deste trabalho e deverá ser objeto de pesquisa futura.

A segunda consideração diz respeito à temporalidade das competências essenciais, justamente porque algumas competências essenciais em princípio parecem ser "menos fortes" do que outras. Com isso, estas competências parecem poder garantir vantagem competitiva sustentável por determinado período, até que os concorrentes consigam de alguma forma copiá-la, replicá-la etc. Quando isso ocorrer, esta competência essencial se tornará então apenas mais uma das capacitações da empresa. 
A questão da temporalidade das competências essenciais foi abordada por CRAIG e GRANT (1999). Segundo estes autores, se uma empresa possui recursos e capacidades superiores aos de seus concorrentes e adota uma estratégia que utiliza esses recursos e capacidades de maneira eficaz (ou seja, possui competências essenciais em relação aos seus competidores), ela poderá criar uma vantagem competitiva. Mas, em termos de capacidade de tirar proveito dessa posição de vantagem competitiva, uma questão decisiva é o período durante o qual a empresa poderá manter sua vantagem. A capacidade de sustentação da vantagem competitiva depende de três características principais de recursos e capacidades: de durabilidade, de transferência e de reprodução; enquanto que a capacidade de empresa obter lucros de sua vantagem competitiva depende da capacidade de apropriação desses retornos.

A durabilidade diz respeito à velocidade com que os recursos e as capacitações de uma empresa se deterioram. A capacidade de transferência diz respeito à capacidade de os rivais atacarem posições de vantagem competitiva, o que depende do acesso aos recursos e capacitações necessárias. Já a capacidade de reprodução é relacionada com a facilidade e rapidez com que os concorrentes desenvolvem os recursos e capacitações nos quais a vantagem competitiva de determinada empresa se baseia. Por fim, a capacidade de apropriação é a capacidade que o proprietário da empresa tem de apropriar os lucros à sua base de recursos.

A terceira consideração diz respeito ao fato de que parece existir um sistema de retroalimentação dentre algumas competências essenciais, sendo difícil discriminar a causa e o efeito de uma competência sobre a outra.

As limitações metodológicas da presente pesquisa são aquelas relacionadas à utilização de estudos de caso como método de pesquisa. Ou seja, os resultados obtidos no artigo não são conclusivos, tampouco exaustivos, e não devem ser generalizados, devendo ser complementados com resultados de pesquisas futuras.

Como recomendação para pesquisas futuras, tem-se o aprofundamento do presente trabalho, através do estudo de outros frigoríficos que não participaram da presente pesquisa, inclusive aplicando a pesquisa em frigoríficos não exportadores. Neste caso espera-se encontrar um baixo nível de ocorrência das competências essenciais descritas no presente trabalho, o que em tese reforçaria a ideia de que a 
presença destas competências essenciais impacta positivamente a atuação dos frigoríficos exportadores. Sugere-se também um maior foco no processo de internacionalização dos principais frigoríficos brasileiros, tendo em vista os acontecimentos recentes neste mercado.

A expectativa é que a presente pesquisa tenha contribuído para o enriquecimento do conhecimento sobre a cadeia agroindustrial da carne bovina no Brasil, principalmente no que se refere á existência de competências essenciais presentes em frigoríficos exportadores de carne in natura.

\section{REFERÊNCIAS}

ABE, C. F. J. e CARVALHO, M . M. Alinhamento entre estratégia e critérios competitivos: um estudo em empresa do setor de bebidas. Revista Produção Online, v.11, n.1, p136-161, mar. 2011.

AMIT, R. e SCHOEMAKER, P.J. Strategic Assets and Organizational Rent. Strategic Management Journal, v.14, p. 33-46, January 1993.

ANDERSON, J.C. e NARUS, J.A. Business market management: understanding, creating and delivering value. 2. Ed. New Jersey: Pearson Education, 2004. 460 p.

BARNEY, J.B. Gaining and sustaining competitive advantage. Reading, MA: Addison-Wesley, 1997. p. 145-162.

BARNEY, J. Strategy Factor Market: expectation, luck and business strategy. The Strategic Management Journal, v.32, n. 10, p. 1231-1241, 1986.

BARROS, A.J.S. \& LEHFELD, N.A.S. Fundamentos da metodologia científica. 2. ed ampliada. São Paulo-SP: Pearson Makron Books, 2000. 122 p. .

BESANKO, D.; DRANOVE, D.; SHANLEY, M. e SCHAEFER, S. Economics of Strategy. 3 ed. New Jersey: Jonh Wiley \& Sons, 2004. 632 p.

BRAGATTO, S. A. Um estudo sobre a padronização na cadeia de carne bovina de corte brasileira. Revista Produção Online, v.8, n.4, mar. 2008.

COLLINS, D.J. e MONTGOMERY, C.A. Competing on resources: strategy in the 1990's. Harvard Business Review, v. 73, p. 118-128, July/August, 1995.

CRAIG, J.; GRANT, R. Gerenciamento estratégico. São Paulo: Littera Mundi, 1999. $138 \mathrm{p}$. 
DAL-SOTO, F.; PAIVA, E.L.; SOUZA, Y.S. Análise de competências organizacionais na internacionalização de empresas da cadeia coureiro-calçadista. RAE, v. 47, n.3, p.40-52, jul./set. 2007.

DOSI, G.; TEECE, D.J. Organizational competencies and sustainability of competitive advantage. University of California at Berkeley, Consortium on Competitiveness and Cooperation. Working Paper, p. 93-11, Feb.1993.

DRANOVE, D.; MARCIANO, S. Kellogg on strategy: concepts, tools, and modelos for practitioners. New Jersey: John Wiley and Sons, 2005. 234 p.

FAHY, J.; SMITHEE, A. Strategic marketing and the resources based view of the firm. Academy of Marketing Review, n.10, 1999,. Disponível em: http://www.amsreview.org/fahy10-1999.pdf. Acesso em: 28 ago. 2010.

FITZROY, P.; HULBERT, J. Strategic management: creating value in turbulent times. New Jersey: John Wiley and Sons, 2005. 432 p.

FLEURY, A.C.; FLEURY, M.T.L. Estratégias competitivas e competências essenciais: perspectivas para a internacionalização da indústria no brasil. Revista Gestão \& Produção, v.10, n.2, p. 129-144, ago. 2003.

GHEMAWAT, P. A Estratégia e o cenário de negócios: texto e casos. Porto Alegre: Bookman, 2000. 380 p.

GRANT, R.M. Contemporary Strategy Analysis. 5 ed. Malden, MA: Blackwell Publishing, 2005. 548 p.

HENDERSON, R.; COCKBURN, I. Measuring Competence: exploring firm effects in drug discovery. In: DOSI, G.; NELSON. R.R. e WINTER, S.G. The Nature and dynamics of organizational capabilities. Oxford. Oxford University Press, 2000, p. 155-182.

HOSKISSON, R.E.; HITT, M.A.; IRELAND, R.D. Competing for advantage. Mason: South-Western, 2004. 395 p.

JOHNSON, G.; SCHOLES, K.; WHITTINGTON. Explorando a estratégia corporativa: texto e casos. São Paulo: Bookman, 2007. 799 p.

KNIGHT, A. K.; CAVUSGIL, S. T. Innovation, organizational capabilities, and the born-global firm. Journal of International Business, v. 35, n.2, p. 124-141, 2004.

LAKATOS, E.M.; MARCONI, M.A. Metodologia científica. 4. ed. São Paulo-SP: Atlas, 2004. 305 p.

LASSERRE, P. Global strategic management. New York: Palgrave McMillan, 2003.p. 454. 
LIPPMAN, S.A.; RUMELT, R.P. Uncertain Imitability: an analysis of interfirm difference in efficiency under competition. Bell Journal of Economics, v. 13, n. 2, p. 111-126, 1982.

PALACIOS, T.M.B.; SOUZA, J.M.M. Estratégias de marketing internacional. São Paulo: Atlas, 2004. 255 p.

PETERAF, M. The Cornerstones of competitive advantage: a resource-based view. Strategic Management Journal, v.14, p. 179-191, $1993 .$.

PIOVEZAN, L.H.; LAURINDO, F.J.B ;CARVALHO, M.M.. Proposta de método para a formulação de estratégia em Pequenas e médias empresas. Revista Produção Online, v. 8, n. 2, jul. 2008.

PORTER, M. Estratégia Competitiva: técnicas para análise de indústrias e da concorrência. Rio de Janeiro: Campus, 1986. 362 p.

PENROSE, E.T. The theory of the growth of the firm. Oxford: Basil Blackwell, 1959.

PRAHALAD, C.K.; HAMEL, G. The core competence of the corporation. Harvard Business Review, maio,, 1990. Disponível em:

<harvardbusinessonline.hbsp.harvard.edu/hbrsa/en/issue/9005/article/90311>. Acesso em: 28 set. 2010.

RITZMAN, M.; AQUILANO, N.; CHASE, R. Fundamentos da administração da produção. Porto Alegre: Bookman, 2001.

RUMELT, R.P. How much does industry matter? Strategic Management Journal, n. 12 , p. 167-185, 1991.

SANCHEZ, R.; HEENE, A. The new strategic management: organization, competition and competence. Nova lorque: John Wiley \& Sons, 2004. 309 p.

SELZNICK, P. Leadership in administration. Evanston, IL: Row Peterson, 1957.

WERNERFELT, B. A resource-based view of the firm. Strategic Management Journal, v. 5, p. 171-180, 1984.

WILK, E.O.; FENSTERSEIFER, J.E. Use of resource-based view in industrial cluster strategic analysis. International Journal of Operations \& Production Management, v. 23, n. 9, p. 995-1009, 2003.

WOLLENHAUPT, S. Metodologia científica: notas introdutórias. Porto Alegre-RS: Bureau Editorial, 2004. 88 p.

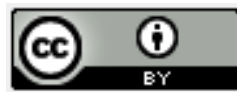

Artigo recebido em 06/10/2011 e aceito para publicação em 03/12/2012. 